\title{
VLOG AS LEARNING MEDIA TO TRAIN ENGLISH FLUENCY AND PUBLIC SPEAKING SKILL
}

\author{
${ }^{\text {a }}$ Zakiyatul Mufidah, ${ }^{\text {b }}$ Miftahur Roifah \\ a,b Universitas Trunojoyo Madura \\ e-mail: zakiyatul.mufidah@trunojoyo.ac.id
}

\begin{abstract}
The collaboration of technology and media can have positive effects on teaching and learning. In modern teaching traditions, teachers must include technology into their teaching and must be able to select a suitable media so they can deliver lessons in the classroom effectively and can achieve the learning goal. This study is going to explore and elaborate the effectiveness of incorporating technology in learning process by using a media to get more engaging learning situation and to know its impacts to the students' learning achievements, especially to their fluency and public speaking skill. To be specific, this study is trying to implement Video Blog (Vlog) as learning media in English speaking subject. The results of the observation show that, training students' fluency and public speaking by implementing Vlog as learning media give positive impacts to the students. Vlog increases students' encouragement in speaking. Vlog can provide fun and enjoyable learning process and it can build confidence.
\end{abstract}

Keywords: technology, learning media, vlog, speaking skill. 


\section{INTRODUCTION}

The teaching traditions now and before are different and cannot be compared. Various changes have occurred as the impact of modernization which brings technology as a great breakthrough in all aspects of people's life. Technology carries an important development in many fields including Education. The former teaching traditions or we called it as conventional teaching traditions value teacher as the main source of knowledge, so that the teaching and learning process goes more into teacher centred learning (Anil, 2016). Monotonous cannot be avoided since there is only one way of knowledge transfer and the students are excluded from the knowledge acquisition. Nowadays, technology takes a big role and makes shifting, bringing more innovations and creations which make the teaching and learning process more colourful. By using technology, there are many preferences teacher can implement to design the teaching method.

With technology now being part of our everyday lives, it is time to rethink the concept of integrating technology into the curriculum to support the learning process. The important role that technology plays in education gives teachers the opportunity to design meaningful learning experiences that embed technology (Eady \& Lockyer, 2003). However, teachers need a media to incorporate technology in their teaching process. Media is defined as all means of communication, whatever its format functioning as the symbol system that teachers use to represent knowledge (Reeves, 1998). The collaboration of technology and media can have positive effects on teaching and learning (Reeves, 1998). Educators and researchers point to the potential of technology to increase motivation and engagement of learners, cater for different learning styles and improve learning outcomes (Eady \& Lockyer, 2003). Therefore, in modern teaching traditions, teachers must include technology into their teaching and must be able to select a suitable media so they can deliver lessons in the classroom effectively and can achieve the learning goal.

In connection with the above discussion, this study is going to explore and elaborate the effectiveness of incorporating technology in learning process by using a media to get more engaging learning situation and to know its impacts to the students' learning achievements. To be specific, this study is trying to implement Video Blog (Vlog) as learning media in English speaking subject. A vlog is a video blog post, created by creating a video of yourself or an event, uploading it to the internet and publishing it within a post on your blog (Sari, 2018). Vlog is chosen as the learning media because Vlog is new trend of technology and recently become popular among students. Vlog gets its popularity since it is published in well known video sharing site, YouTube. The idea of using Vlog as the learning media is giving chance to the students of English speaking class in practicing their English while they try to create Vlog containing of tourism promotion. So, the Vlog will contain of activities of promoting one of Madura tourism destination places since this study is conducted in English study program, University of Trunojoyo Madura.

Tourism promotion is designed as the content of the Vlog in this study because in speaking class, students are trained to not only being fluent in English speaking but also they must be able to deliver information clearly to achieve the learning outcomes of being good public speaker. Here using Vlog is considered as innovation of teaching because previously the English speaking class never apply this learning media and the activities of the students are just drilling, classroom game, interview, role play, etc which all the activities do not incorporate with technology and just ended inside the classroom. 
By using new innovation which is the collaboration of technology and media, it is expected that the students can get new atmosphere of learning process so they will be more motivated, more engaging and get more improvement in their learning outcomes. For further discussion of this study will focus on students' performance in the Vlog, how they can promote one of Madura destination places in good English and good public speaking. After the Vlog is made, the video will be evaluated from many points of view to get feedback from the lecturers whether or not there are mistakes or errors that the students need to know from their performance so they can learn and improve their skill in the future.

The study of Vlog in the teaching of English speaking subject has been conducted by several researchers with various issues of discussion. The connection between one study and another study is all of them use Vlog as the learning media but with different purposes. The first study is conducted by Dr. Beena Anil from Department of English SDNB Vaishnav College for Women, Chromepet, Chennai, India. Dr. Anil study uses Vlog to top-up students second language talk time. Dr. Anil mentions that Vlog can be used in an English teaching classroom to improve students' oral communication. Vlog helps students to practice English even outside the classroom, give instant teacher's feedback about their performance and can watch fellow students' performance. She further discussed that teachers should consider Vlog to boosts students speaking time. This application helps students to communicate more to improve vocabulary, to understand grammatical aspects and to erode shyness. When students start to expand the boundary of learning even outside the classroom with same liveliness with the same set of people but in a different milieu is considered to be a healthy learning approach. The results of her study conclude that Vlogging is a good oral communicative application. This process is a trial and error method where students would learn from their errors with the help of a facilitator. Implementation of such applications will have technical glitches too but proper outlook will help the vlogging component much smoother. When students are well- versed in using such applications their speech quality steadily improves after a stipulated time. The output of vlog can be used measure the error occurrence and speech fluency so that students' development can be enlightened and worthy of evaluating their language competency (Anil, 2016).

The second study which uses Vlog as the learning media is a study conducted by Imam Masofa and Alfi Laili Rahmah. The title of their study is implementing Vlog for innovation in ELT practices. The objectives of this study are to find out how the teacher implements vlog and how the students' speaking performance improves by using vlog in speaking descriptive text. The assessment of implementing vlog for innovation in ELT Practices to the Students of Excellent School of Amanatul Ummah was analyzed by using Nakamura's scoring rubric which consists of organization, fluency, pronunciation, vocabulary and performance. The results of this research can be formulated as follows: 1) Students can speak based on rhetorical steps in their vlog. 2) Students' performances show self-confident in their vlog. 3) Students' fluency is less hesitant in their vlog. 4) Students' vocabulary uses variety of words in their vlog (Masofa, 2018).

The third study is conducted by Izzah Maulidah whom she analyzes Vlog as the mean to improve students' speaking. Her study is aimed at exploring these three terms; a) Vlog and its tools, b)Vlogging stages, and c) Significances of it in improving students' speaking ability. By supporting Vlog with a sophisticated vlogging stages 
and a proper scoring reflection as a feedback, it is expected to improve students' speaking ability in English (Maulidah, 2018).

The previous three studies above can be the references for this study because this study also takes similar issue about Vlog as learning media. However, this study brings different discussion which looking at the implementation of Vlog to train the fluency of English and giving opportunity to students in practicing to be good public speaker. Finally this study also wants to explore how far is the effectiveness of Vlog as learning media in bringing new innovations in the teaching of English speaking subject.

\section{REVIEW OF LITERATURE}

\section{Technology and Learning Media}

Learning media and technology has become an integral part of most teaching and learning process. Teaching with media and technology is brain friendly (Walker, 2004). It means that students are no longer limited by the walls of a classroom or the knowledge of a single textbook, so the world is available to most classrooms. The reasons why teachers should bring technology to the classroom according to (Walker, 2004) are because 1) technology is not limited by the classroom walls. 2) It provides an equal opportunity for every student to learn. 3) Technology is more in tune with the way our students learn today. 4) Technology is so much a part of the real world that to limit its use in the classroom is to limit our students' ability to compete in the world.

Media can cause learning (Kozma, 1994). The potential relationship between media and learning is that learning is not simply a passive response to instruction's "delivery." Rather, learning is an active, constructive, cognitive, and social process by which the learner strategically manages available cognitive, physical, and social resources to create new knowledge by interacting with information in the environment and integrating it with information stored in memory. From this perspective, knowledge and learning are the result of a reciprocal interaction between the learner's cognitive resources and aspects of the external environment. Moreover, this interaction is strongly influenced by the extent to which internal and external resources fit together (Kozma, 1994).

Early attempts to review research findings in light of the new assumptions noted above suggest that "learning with media [is] a complementary process within which representations are constructed and procedures performed, sometimes by the learner and sometimes by the medium (Kozma, 1994)."

\section{Vlog}

A vlog is a combination of video and blog (blog itself is a mix of web and log). Blog is a forum for anyone who wants to express opinion, or share information personally or socially. Blogs can be used for writing and Vlog can be used for communication (Anil, 2016).

Vlog helps students to self-monitor their performance before they post their Vlog to their teacher and they can listen and do sufficient modification to their level of understanding. If the teacher feels that a student could improve in his/her presentation, a second try can be done easily. Another benefit of using Vlog is giving feedback about students' performance. The teacher can focus or allot more time on the students' prospective vulnerable area of learning. Teacher can offer advance to students that can 
be viewed whenever students want to listen to and do necessary changes in the passage of practice (Anil, 2016).

Sun (2009) cited by (Maulidah, 2018) explains several stages in Vlogging. The first stage is conceptualizing in which it is involved in making plan of vlogs. The second stage is brainstorming. In Brainstorming stage, students begin to create the concept of vlog; what they want to say in the video. They make a script and translate it from host language. The third stage is articulation. In other words, we may call articulation as action in which students do rehearsals before starting to shoot their speaking activities. Somehow, it is possible to make editing for the video before uploading. The final stage is evaluation. In this stage, the students do activity as selfcorrection related to their project. They may also ask their friends to give an opinion about it. If they found mistakes in terms of meaning, form or etc, they may redo a vlogging.

\section{METHOD}

\section{Respondents}

The respondents of this study are students of English study program, University of Trunojoyo Madura. The numbers of the respondents are all students who joined Speaking I class but they will be divided into groups so in making the Vlog they will conduct it not individually. The respondents are majoring English, so they have the basic skills of English yet they still have some problems in several areas especially in the fluency and confident.

\section{Instrument}

The study is conducted by observing the students' performance of how the implementation of Vlog as media learning in the teaching and learning process of speaking subject. The researcher uses the observation to note all of the activities of the teacher in the class to give a real and valid data. The researcher will also use the rubric of speaking assessment to look how at the students' speaking ability. The students' speaking then will be assessed and scored based on the rubrics below:

1. Good fluency: Speech is effortless and smooth

2. Good pronunciation: No or almost mispronunciation

3. Goof vocabulary: There is a rich variety of words and almost all of them are correctly

4. Good performance: Speaks confidently loudly and naturally, mastering good public speaking skills (good eye contacts, good body movement and gestures, good voice and intonation, etc)

\section{Procedures}

In conducting this study, there are several stages to be followed. The first is overview and preparation, second is process, and third is evaluation. In the first stage, the students find out knowledge and information about Vlog and the procedures of how to create it. After that they must design the form of the Vlog they are going to create, make a concept of the Vlog, consult the language they are going to use, and practice it. The second stage is the process of recording and making Vlog by visiting one of tourism destination places in Madura and promotes it with good English. The last stage is evaluation. In this stage the result of the Vlog is published in YouTube 
and watch together in the classroom. Students will review, analyze and evaluate their own performance in the Vlog for getting feedback.

\section{Data Analysis}

The data is analysed by using qualitative analytic strategies to collect the data of the teacher during teaching-learning process in the classroom. The result of the observation will be interpreted and described to get the findings for the discussion. The product of the students' Vlog will be scored from the fluency and the public speaking. The aspects of the fluency which are going to analysed and discussed are from the smoothness of the speaking, the use of grammatical structure, the selected diction, and the pronunciation. Moreover the public speaking will be assessed and analysed from the gestures, eye contacts, body movement, attractiveness, persuasion, confidence and interaction. If all the aspects have been analysed and discussed so the conclusion can be drawn whether or not it is effective to use Vlog as learning media to train English fluency and public speaking.

\section{RESULT AND DISCUSSION}

\section{Vlog as Media Learning to Train English Fluency and Public Speaking}

Students find it hard to speak English despite the fact that they have the basic knowledge of the language due to the fact that they lack of exposure in English activities. Their English is passively used so they still get difficulties to speak smoothly with no errors or mistakes. Some students still hesitate to speak freely with long duration of talking because they do not engage whether with the given topic or with the classroom activities. Students' difficulties in speaking before the use of Vlog as the learning media can be summarized as follows:

1. Students show hesitate in their speaking

The indicators of showing hesitate in speaking is students often stop during their speaking, use too many err, umm, eee etc or awkward pauses, in certain occasion students still read their notes.

2. Students lack of vocabularies

The indicators of showing lack of vocabularies are the students often use inappropriate word choice, use only simple and daily used vocabularies, cannot differentiate formal or informal, or vocabularies based on the field, and still often ask their friends or even the lecturer : what is the English of ....

3. Students unable to use correct grammatical structure Students in their speaking often missed identify gender of the pronoun between he/ she, students cannot use subject verb agreement correctly, and cannot use tenses properly based on the function.

4. Students cannot pronounce certain words correctly

Many mispronounced words happen especially for the words with e.g. ending -ed, or words with minimal pairs, and often mumbling when they are talking.

By implementing Vlog as new innovation in the teaching of speaking subject as the learning media, results show that when the students are given the project to make Vlog their first reaction is very excited. They feel enthusiast because they spend most of their time to watch other people's Vlog, and now they get an opportunity to create 
their own Vlog. Their excitement and enthusiasms lead them to work harder to make their Vlog good and interesting to watch.

During the preparation stage, it can be seen that the students' motivation is increased because they have good engagement to the activities. The preparation process make them doing several activities; create the concept of the Vlog (they can get inspiration by watching other people's Vlog) and prepare the content of the Vlog (What information they are going to deliver, how's the delivery language etc).

In this stage the implementation of Vlog as learning media gives students some benefits as follows:

1. It can raise students' positive awareness of using technology. Before conducting this project, students probably just become the user or the consumer of other people's Vlog and they cannot get academic experiences beside the entertainment.

2. Giving students project to make Vlog, they can get chance to develop their creativity. In the preparation stage, students must design and concept their Vlog thus their creativity in this stage is challenged. If they have good creativity so they can produce a good and interesting Vlog so the Vlog can attract viewers to watch.

3. Students can learn how to build a good teamwork by doing this project. They can learn how to communicate with their friends, having discussion and sharing opinions.

After getting through the preparation stage, students start to practice before they shoot or record their own Vlog. Students doing rehearsal so they can find out problems of their speaking when they deliver the content of the Vlog. In this stage, by using Vlog as learning media students can drill themselves to speak naturally and confidently. In rehearsal stage, students can focus to their fluency and confidence, if they find out doing mistakes or cannot do the performance well they can redoing or repeat the activities several times until they feel satisfied or until they can achieve good performance.

Furthermore, after conducting all the process, the results of the students' Vlog will be evaluated and reviewed deeply to know whether or not by doing Vlogging students can train their fluency and public speaking. Overall, the results show that the students' performance in their Vlogs is considered success because they have gone through practice or rehearsal stage before. To be specific, in this discussion there will be 3 Vlogs that will be reviewed and analyzed deeply.

The first Vlog is created by students from speaking IA class. The speakers of this Vlog are 4 female students who talks about the history of Ratu Ebhu, a graveyard site in Bangkalan, Madura. The duration of the Vlog is 4 minutes. Overall, the students can did the Vlog nicely and they can deliver the content well, so they successfully persuade viewers to visit Ratu Ebhu. Below the description of their Vlog is explained in details by using above mentioned rubrics. 


\section{Fluency}

The first speaker in this Vlog, speaks very well. She speaks very smooth and with no hesitation. Her speaking is effortless even though for several times she looks at her note.

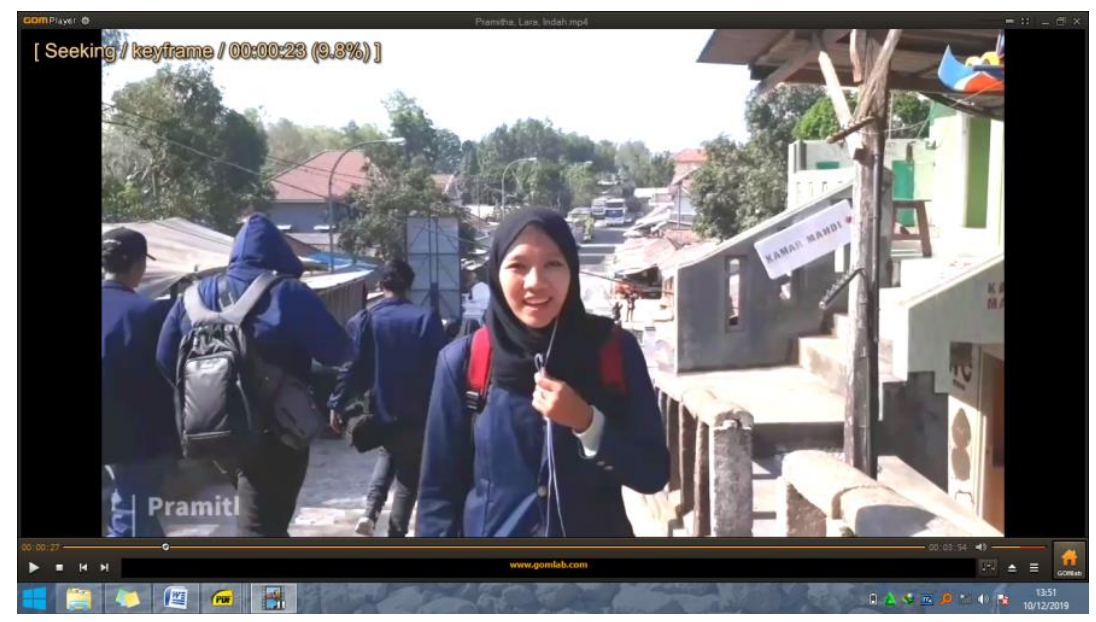

The next speaker of this Vlog speaks less smooth than the previous speaker. She often repeats words or sentences several times. In the middle of her speaking, sometimes there are pauses which indicate that she gets difficulties to continue her sentences.

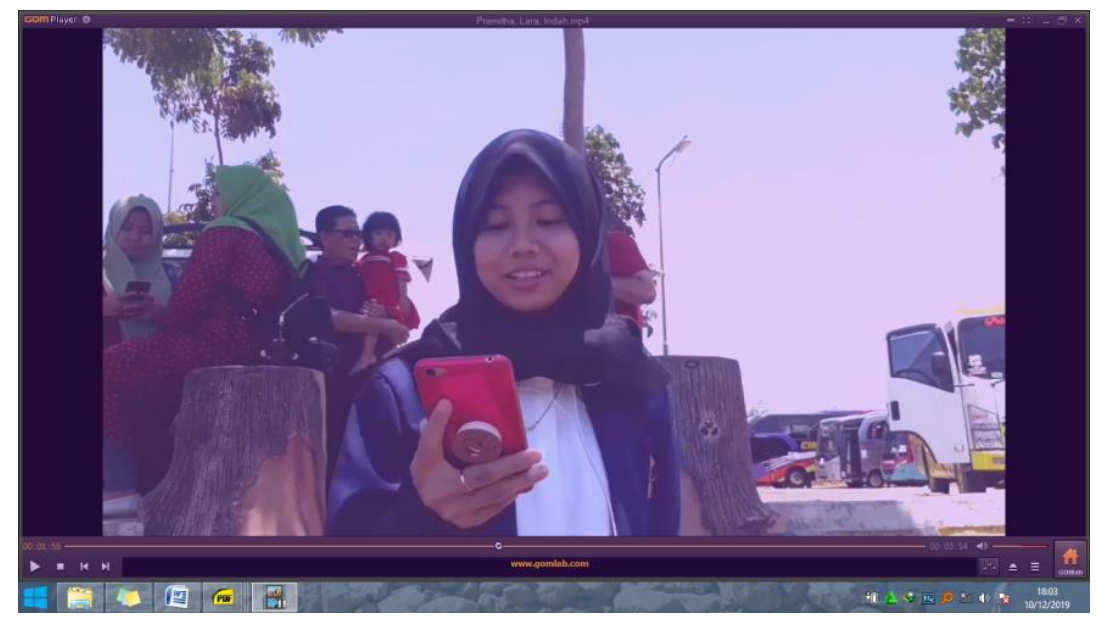

\section{Pronunciation}

The first speaker of the first Vlog has good clarity. Her speaking is clear and understandable. Her pronunciation is not perfect but considered as good. She also has some mispronunciations, but viewers still can catch what she means. In contrast, the second speaker's pronunciation is a bit unclear and mumbling. Almost every word is pronounced incorrectly. It makes viewers difficult to catch what she means and it results in the content of the Vlog cannot be well delivered.

\section{Vocabulary}

The first speaker's vocabularies are fine; it means that she uses appropriate vocabularies based on the context. However, she doesn't show great level of vocabularies, just intermediate level. The second speaker often uses wrong dictions, 
so the words sometimes do not suit the context. So her vocabularies do not match with the whole ideas of her sentences.

\section{Performance}

The performance of both speakers in the first Vlog is good. The indicators are they show good confidence when they are delivering the content of the Vlog despites of some mistakes they have. They are very relax and natural. They have good eyes contact and gestures. It shows that they have good public speaking because they can perform well in public.

The second Vlog which is going to be reviewed is created by students from IB class. The duration of the Vlog is 7 minutes and it talks about beautiful spots in Pelalangan Hills Bangkalan, Madura. The speakers of the second Vlog are 4 students; 3 female students and 1 male student. They talk alternately.

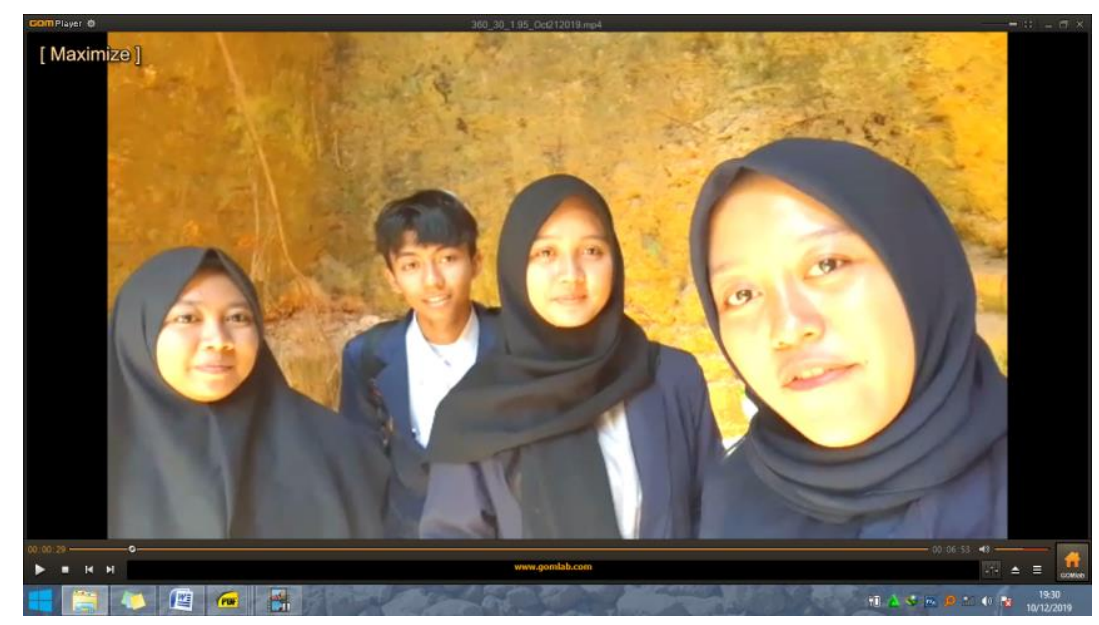

The overall performance of the second Vlog is great. All speakers can deliver the content very well and very clear. Their Vlog looks so natural and so interesting. Specifically the details of their Vlog will be discussed below:

\section{Fluency}

The speakers in the second Vlog speak very natural as they have usual conversation in daily. They speak with no hesitation and very smooth. They enjoy their talking a lot, so it can brings good atmosphere to the viewers to also enjoy their explanation. They have little problems with the language, so the content of the Vlog can be well delivered.

\section{Pronunciation}

The pronunciation of the speakers in the second Vlog is clear. They speak with loud voice, good intonation, and good stressed.

\section{Vocabulary}

The speakers in the second Vlog do a good job in taking the words they used. They really know how to choose the words, so that the vocabularies are easily understood. They can match between the contexts of the speaking with the words choice. Overall, they have good dictions and rich too. 


\section{Performance}

The speakers perform very well in the second Vlog. They have good confidence and able to speak naturally. They combined every aspect of public speaking into good performance; they have good eyes contact, gestures and body movement also great. They do not show nervous or under pressure even they speak in front of camera. It shows that they have good teamwork so they can provide good performance.

The last Vlog is made by students from Speaking IC class. The duration is 5 minutes and talking about Toroan waterfall in Bangkalan, Madura. The speaking content of the third Vlog is less than the other two Vlogs. They attach too many pictures so viewers just get little information of the place. Their performance will be evaluated below:

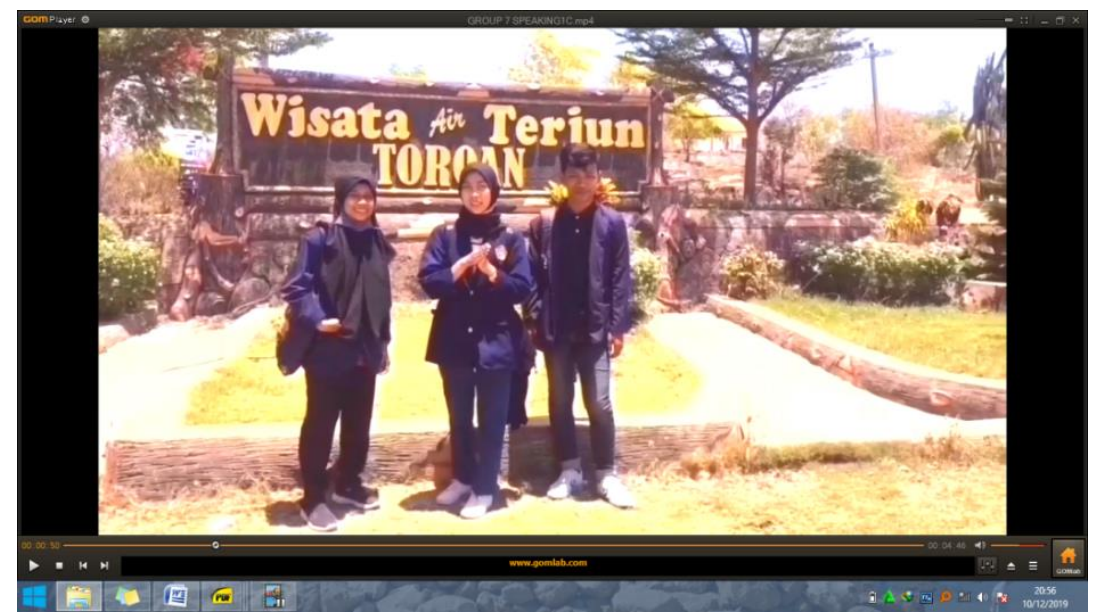

\section{Fluency}

The level of fluency of the speakers in the third Vlog is just enough. It means that their speaking is quite clear and easy to understand, yet at certain point they sometimes repeating words or sentences. Also, they often see their note to help delivering the content of the Vlog.

\section{Pronunciation}

The speakers of the third Vlog get difficulties in pronunciation part. Several words are pronounced incorrectly.

\section{Vocabulary}

The speakers do not really use variety of vocabularies. Sometimes their choices of words are inappropriate, but it is still understandable.

\section{Performance}

The speakers seem to have lack of confidence because they often speak while they are looking at their note. They just have small body movement and gestures, also have little eyes contact.

The results above show that, training students' fluency and public speaking by implementing Vlog as learning media give positive impacts to the students. Vlog increases students' encouragement in speaking. EFL students have limited chance to 
express their speaking performance. Students only practice their English speaking in the class or special event that used English as tool of communication. By providing vlog as one of teaching media, students will get more chance to talk outside the class. Vlogging force them to talk and tell their ideas in English. As the result, their speaking ability will increase gradually (Maulidah, 2018). Vlog is one of teaching innovation that can be implemented in the teaching of speaking subject. It provides better learning process because it correlates technology and media learning. Maulidah (Maulidah, 2018) mentions that one benefit of implementing Vlog as learning media is can cause autonomous learning. Students will get their meaningfulness in their study. They also get freedom to manage their ideas related to their leaning process. However, because doing Vlog is the first experience for students, they still lack of readiness and there are many things that need to be improved.

\section{CONCLUSION}

Vlog is good learning media for students to train their fluency and public speaking because Vlog is connected with technology. Many benefits students can get by implementing this media in their learning process. It gives them new experiences which they do not get before, so they can feel more engaging with the activities. Students are encouraged to learn and practice more their speaking ability because Vlog can provide fun and enjoyable learning process. Besides, students can also learn how to deliver certain topics with good public speaking skill. It can promote good presentation in students' speaking performance. They can build their confidence by trying to talk to audiences.

\section{REFERENCES}

Anil, B. (2016). Top-Up Students Second Language Talk Time through Vlogs. Indonesian Journal of EFL and Linguistics, 1(2), 129-143. https://doi.org/10.21462/ijefll.v1i2.9

Eady, M. J., \& Lockyer, L. (2003). Numerical study of the three-dimensional flow in the axial flow rotor with tip clearance. Shanghai Jiaotong Daxue Xuebao/Journal of Shanghai Jiaotong University, 37(9), 1480-1483.

Kozma, R. (1994). The influence of media on learning: The debate continues. School Library Media Quarterly, 22(4), 1-13.

Masofa, I. (2018). Implementing vlog for innovation in ELT practices. Proceeding of the 65th TEFLIN In Ternational Conference, Universitas Negeri Makasat, Indonesia., 65 No 1, 172-179.

Maulidah, I. (2018). Vlog: the Mean to Improve Students' Speaking Ability. 145(Iconelt 2017), 12-15. https://doi.org/10.2991/iconelt-17.2018.3 
Reeves, T. C. (1998). The impact of media and technology in schools. A Research Report Prepared for The Bertelsmann Foundation, 1-44. Retrieved from http://citeseerx.ist.psu.edu/viewdoc/download?doi=10.1.1.129.9680\&rep=rep1 \&type $=$ pdf\%5Cnpapers://e97baf73-a10d-438d-985bbee59744e11f/Paper/p10045

Sari, P. (2018). Using Vlog in the Youtube Channel as a Means To Improve Students' Motivation And Confidence to Speak English in Intermediate 1 Level of LB-LIA Jambi. International Journal of Language Teaching and Education, 1(1), 38-44. https://doi.org/10.22437/ijolte.v1i1.4596

Walker, D. E. T. (2004). The Importance of Media in the Classroom. What Every Teacher Should Know About Media and Technology, 09, 1-7._2000-AN 